\title{
Community poverty level influences time to first pediatric rheumatology appointment in Polyarticular Juvenile Idiopathic Arthritis
}

Nayimisha Balmuri $\mathbf{1}^{12^{*}+} \mathbb{D}$, William Daniel Soulsby ${ }^{3+}$, Victoria Cooley ${ }^{2}$, Linda Gerber ${ }^{2}$, Erica Lawson ${ }^{3}$, Susan Goodman ${ }^{1,2}$, Karen Onel ${ }^{1,2}$, Bella Mehta ${ }^{1,2}$ and for the CARRA Registry Investigators,

\begin{abstract}
Background: The impact of social determinants of health on children with polyarticular juvenile idiopathic arthritis $(p J / A)$ is poorly understood. Prompt initiation of treatment for $p J I A$ is important to prevent disease morbidity; however, a potential barrier to early treatment of pJIAs is delayed presentation to a pediatric rheumatologist. We examined the impact of community poverty level, a key social determinant of health, on time from patient reported symptom onset to first pediatric rheumatology visit among pJIA patients enrolled in the Childhood Arthritis and Rheumatology Research Alliance (CARRA) Registry.

Methods: This is a cohort study of pJIA patients in the CARRA registry who lived in the United States from July 2015-February 2020. The primary exposure was community poverty level derived by geocoding patient addresses. The primary outcome was time to first rheumatology appointment. Kaplan-Meier analysis was performed to analyze time to first rheumatologist visit, stratified by community poverty and family income. Log-rank tests were used to identify differences between groups. Adjusted cox proportional-hazards models were used to determine the relationship between community poverty level and time from onset of disease symptoms to date first seen by rheumatologist.

Results: A total of 1684 patients with pJIA meeting study inclusion and exclusion criteria were identified. Median age of onset of pJIA was 7 years (IQR 3, 11), 79\% were female, 17.6\% identified as minority race and/or ethnicity, and $19 \%$ were from communities with $\geq 20 \%$ community poverty level. Kaplan-Meier analysis by community poverty level ( $<20 \%$ vs $\geq 20 \%$ ) yielded no significant differences with time to initial presentation to a pediatric rheumatologist $(p=0.6)$. The Cox proportional hazards model showed that patients with $\geq 20 \%$ community poverty level were 19\% less likely (adjusted HR 0.81, 95\% Cl 0.67-0.99, $p=0.038$ ) to be seen by a rheumatologist compared to patients with $<20 \%$ community poverty level, at the same time point, after adjusting for sex, race/ethnicity, insurance, education level, morning stiffness, RF status, and baseline CHAQ.
\end{abstract}

\footnotetext{
*Correspondence: nbalmur1@jhmi.edu

${ }^{\dagger}$ Nayimisha Balmuri and William Daniel Soulsby contributed equally to this work.

${ }^{1}$ Hospital for Special Surgery, New York, NY, USA

2Weill Cornell Medicine, New York, NY, USA

Full list of author information is available at the end of the article
}

\section{$\triangle B M C$}

(c) The Author(s). 2021 Open Access This article is licensed under a Creative Commons Attribution 4.0 International License, which permits use, sharing, adaptation, distribution and reproduction in any medium or format, as long as you give appropriate credit to the original author(s) and the source, provide a link to the Creative Commons licence, and indicate if changes were made. The images or other third party material in this article are included in the article's Creative Commons licence, unless indicated otherwise in a credit line to the material. If material is not included in the article's Creative Commons licence and your intended use is not permitted by statutory regulation or exceeds the permitted use, you will need to obtain permission directly from the copyright holder. To view a copy of this licence, visit http://creativecommons.org/licenses/by/4.0/ The Creative Commons Public Domain Dedication waiver (http://creativecommons.org/publicdomain/zero/1.0/) applies to the data made available in this article, unless otherwise stated in a credit line to the data. 
Conclusion: In this study of pJIA patients in the CARRA registry, increased community poverty level is associated

with longer time to presentation to a pediatric rheumatologist after symptom onset.

\section{Background}

Juvenile idiopathic arthritis (JIA) includes a heterogeneous group of chronic childhood inflammatory arthritides that can lead to significant morbidity through damaging joints and impairing both physical function and growth. Rheumatoid factor (RF) positive and RF negative polyarticular JIA (pJIA) are two forms of arthritis that affect 5 or more joints. Among subtypes of JIA, children with pJIA are more likely to experience prolonged periods of active disease [1] with an increased risk for a relapsing and remitting course throughout the lifespan [2]. Irreparable damage to the joints and surrounding tissue is known to occur early in the course of disease in as many as $60 \%$ of patients with pJIA [3, 4]. In order to prevent this damage, it is imperative to bring disease under control as rapidly as possible underscoring the importance for a child with new-onset pJIA to present to a pediatric rheumatologist early on in the disease course [5].

Social determinants of health $(\mathrm{SDH})$ such as access to public or private health insurance, guardian's level of education, family income, and poverty level have all been associated with barriers to subspecialty follow up in children with chronic diseases in the United States $[6,7]$. As SDH are not consistently reported in registries, area-based socioeconomic measures can be used as a proxy to provide insight into patients' socioeconomic status. Features of community deprivation such as poverty are associated with sparse community resources needed for good health [8] with poor health outcomes consistently reported in communities where $\geq 20 \%$ of the population lives below the poverty level [9-11]. Delayed diagnosis and presentation to a rheumatologist has been described in adult rheumatoid arthritis [12-14] and reported in international cohorts of patients with juvenile idiopathic arthritis [15-17]. However, the effect of community poverty, a key social determinant of health, on time to presentation to a pediatric rheumatologist has not been described.

Evaluating disparities in delays to care is an important initial step toward identifying ways to overcome barriers to equitable care and to improve disease outcomes. In this study, we aimed to examine the effect of community poverty on time to first pediatric rheumatology visit among pJIA patients enrolled in the Childhood Arthritis and Rheumatology Research Alliance (CARRA) Registry, a large cohort of pJIA patients from North America.

\section{Methods \\ Study design}

We analyzed baseline data collected from the pJIA cohort in the CARRA Registry. The CARRA Registry includes data from children with rheumatic diseases from 70 sites in North America with all but four of these centers located in the United States (US). Patients diagnosed with pJIA prior to age 16 are enrolled into the Registry by a pediatric rheumatologist before the age of 21 . Research personnel enter pertinent data from each CARRA site at the time of initial and follow up patient visits. Data utilized for this study were collected from April 2015 through February 2020.

\section{Analytical sample}

Inclusion criteria were US residency and pJIA diagnosis with recorded $\geq 5$ joints involved in first 6 months of disease. Exclusion criteria were invalid US zip code and additional diagnosis of systemic inflammatory or autoimmune disease. Approval for exemption was obtained from the Hospital for Special Surgery and University of California, San Francisco Institutional Review Board.

\section{Primary exposure}

The primary exposure was community poverty level. Five-digit zip-codes of the addresses where patients were located at symptom onset were queried. We geocoded these individual zip-codes to link patients to specific census tracts and census blocks. We obtained census tract and block-level socioeconomic variables from the 2015-2019 American Community Survey (ACS) data using the Geographic Information Systems. These geographic units are designed to be homogeneous with respect to population characteristics, economic status, and living conditions [18]. Community poverty level ascertained by utilization of ACS information is based off of percentage of peoples in a given census tract who live below the federal poverty line based on income level. The census-tract level is highly sensitive to gradients in health $[8,19]$ with poor health outcomes consistently reported in communities where $\geq 20 \%$ of the population live below the poverty level [9-11]. Therefore, community poverty level as a primary exposure was dichotomized as a concentration less than $20 \%$ and greater than or equal to $20 \%$.

\section{Primary outcome}

The primary outcome is time from symptom onset to presentation to the pediatric rheumatologist. Date of 
symptom onset, date of first presentation to a pediatric rheumatologist, and subject's medical history was obtained from provider questionnaires completed using information from the family and verified by medical records. From these data, the primary outcome of the time from symptom onset to presentation to a pediatric rheumatologist was calculated.

\section{Study covariates}

De-identified demographic information and clinical characteristics from the baseline registry visit were analyzed. Demographic information included patient age, reported race and ethnicity, reported household income, insurance status, highest level of guardian education. Clinical characteristics such as duration of patientreported morning stiffness, RF antibody status, and disease activity and disability at first pediatric rheumatology visit were queried. Disease activity was calculated using the Clinical Juvenile Arthritis Disease Activity Score (cJADAS) [20]. Disability was assessed with the Child Health Assessment Questionnaire (CHAQ) [21].

Race and ethnicity were self-reported and defined as White, Asian, Black/African American/African or AfroCaribbean, Hispanic/Latino/Spanish origin, other, and prefer not to answer. Self-reported household income level was defined as $<\$ 25,000, \$ 25,000-49,999$, $\$ 50,000$ 99,9999, and $\$ 100,000+$. Parent/guardian education level was defined as high school or less, college (including 14-year college, junior college, or technical school), and graduate school. Insurance status was categorized as public insurance (including Medicaid, a state specific children's insurance plan, and military health care), private insurance, or other (including no insurance, more than one, non-US insurance, self-reported as other, or missing).

\section{Statistical analysis}

Descriptive statistics were generated to describe the study population using $\mathrm{N}(\%)$ and median (IQR). Kaplan-Meier curves were generated to visualize time from symptom onset to first rheumatologist visit using dichotomized community poverty as the primary exposure. Log-rank tests were used to identify any differences between groups. Cox proportional-hazards models stratified by age at baseline were utilized to estimate hazard ratios for the relationship between community poverty, as a primary predictor, and time to presentation to a pediatric rheumatologist as the defined event of interest or hazard. Analyses were adjusted for demographic features, including sex and race/ethnicity; key variables associated with SES, including insurance and reported family education level; and variables associated with disease characteristics like patient reported morning stiffness and baseline CHAQ to account for disease severity and disability and IgM RF initial to account for more aggressive disease due to seropositivity. Collinearity between patient reported morning stiffness and baseline cJADAS was assessed with a Wilcoxon rank sum test, and morning stiffness was selected in the final model due to missingness of cJADAS values. Statistical significance was evaluated at the 0.05 alpha level, and 95 $\%$ confidence intervals were generated for all predictor estimates. All analyses were performed in R Core Team (Survival and Tidyverse, version 4.0.3, 2019, Vienna, Austria).

\section{Sensitivity analysis}

While community poverty level was calculated based on a subject's zip code of residence at first rheumatologist visit, household income level was self-reported in the Registry. Reported income had a large number of missing data (26.7\%). Therefore, we conducted a sensitivity analysis using family reported income as the primary predictor of time to first rheumatologist visit to assess for validation between family-reported income and investigator-calculated community poverty level. This sensitivity analysis was performed for both the KaplanMeier analysis and the Cox-proportional hazards model.

\section{Results}

\section{Baseline characteristics}

This study sample included 1684 participants who met inclusion and exclusion criteria for our study, out of the 3637 pJIA participants in the CARRA Registry. The majority of those excluded did not meet the requirement of 5 or more active joints within the first 6 months of disease, therefore not meeting ILAR classification criteria for polyarticular JIA or non-residency in the United States. The baseline characteristics of the 1684 included patients are summarized in Table 1 . The median age of onset of pJIA was 7 years (IQR 3, 11), 79\% were female, $17.6 \%$ identified as minority race and/or ethnicity; $19 \%$ were from communities with $\geq 20 \%$ community poverty level, and $25.5 \%$ utilized public insurance. More than half of the cohort reported a family income greater than $\$ 50,000$ per year (53.2\%) while $27 \%$ of the total cohort did not report family income. Guardian education was college level or greater among $56.2 \%$ of participants though there was significant missingness also for this key demographic feature (28.4\%). The geographical distribution of the study patients in the United States are shown in Fig. 1.

\section{Clinical outcomes}

Median time from onset of symptoms to first pediatric rheumatology visit was 3 months (IQR 1 month, 6 months); $20 \%$ of the cohort did not have this information available. Key clinical features obtained included 
Table 1 Demographic and clinical characteristics of pJIA patients enrolled in this CARRA Registry cohort

\begin{tabular}{|c|c|}
\hline Characteristic & Total $N=1684$ \\
\hline \multicolumn{2}{|l|}{ Sex } \\
\hline Female & $1322(79 \%)$ \\
\hline Male & $362(21 \%)$ \\
\hline Age at diagnosis - Median (IQR) & $7.0(3.0,11.0)$ \\
\hline \multicolumn{2}{|l|}{ Race/Ethnicity } \\
\hline White & $1246(74 \%)$ \\
\hline Asian & $53(3.1 \%)$ \\
\hline $\begin{array}{l}\text { Black, African American, African, or } \\
\text { Afro-Caribbean }\end{array}$ & $63(3.7 \%)$ \\
\hline Hispanic, Latino, or Spanish origin & $167(9.9 \%)$ \\
\hline Other & $130(7.8 \%)$ \\
\hline Prefer not to answer & $25(1.5 \%)$ \\
\hline \multicolumn{2}{|l|}{ Household Income } \\
\hline$<\$ 25,000$ & $150(8.9 \%)$ \\
\hline$\$ 25,000-49,999$ & $188(11.2 \%)$ \\
\hline$\$ 50,000-99,999$ & $414(24.5 \%)$ \\
\hline$\$ 100,000+$ & $483(28.7 \%)$ \\
\hline Prefer not to answer or missing & 449 (26.7\%) \\
\hline \multicolumn{2}{|l|}{ Community Poverty Level } \\
\hline Less than $20 \%$ & $1368(81 \%)$ \\
\hline Greater than or equal to $20 \%$ & $316(19 \%)$ \\
\hline \multicolumn{2}{|l|}{ Parent/Guardian Education Level } \\
\hline High school or less & $260(15.4 \%)$ \\
\hline $\begin{array}{l}\text { College (1-4 year college, junior } \\
\text { college, or technical school) }\end{array}$ & $656(39 \%)$ \\
\hline Graduate school & $289(17.2 \%)$ \\
\hline Prefer not to answer or missing & 479 (28.4\%) \\
\hline \multicolumn{2}{|l|}{ Insurance } \\
\hline Public & $430(25.5 \%)$ \\
\hline Private & $1123(66.7 \%)$ \\
\hline None/Other/Non-US/More than one & $131(7.8 \%)$ \\
\hline \multicolumn{2}{|l|}{ Patient Reported Morning Stiffness } \\
\hline$<=15 \min$ & $1114(66.2 \%)$ \\
\hline$>15 \min$ & $438(26 \%)$ \\
\hline Missing & $132(7.8 \%)$ \\
\hline Baseline CJADAS & $7.5(3.0,12.0)[2]$ \\
\hline Unknown & 641 \\
\hline Baseline $\mathrm{CHAQ}$ & $0.25(0.00,0.87)[2]$ \\
\hline Unknown & 130 \\
\hline \multicolumn{2}{|l|}{$\lg M \mathrm{RF}$} \\
\hline Positive & $309(18 \%)$ \\
\hline Negative & 1204 (71\%) \\
\hline Not performed & $171(11 \%)$ \\
\hline \multicolumn{2}{|l|}{ Anti-CCP } \\
\hline Positive & $252(15 \%)$ \\
\hline Negative & 786 (47\%) \\
\hline Not performed & 646 (38\%) \\
\hline
\end{tabular}

self-reported morning stiffness, of which the majority of the cohort reported none or less than $15 \mathrm{~min}$ (66.2\%). Median baseline cJADAS was 7.5, though we were unable to calculate for $38 \%$ of the cohort due to missing joint counts. Of note, in this cohort, cJADAS and morning stiffness were found to be collinear and strongly associated in distribution with a Wilcoxon rank sum test $(p<0.001)$. Baseline median CHAQ was 0.25 .

\section{Time to first pediatric rheumatologist visit}

In unadjusted analysis, there was no statistically significant difference $(p=0.6)$ between time to first pediatric visit for newly diagnosed pJIA patients when analyzing by the primary exposure- community poverty level of < $20 \%$ versus $\geq 20 \%$. The median time to presentation to care for both these groups was 3 months (95\% CI 2-3 months). Figure 2 demonstrates this Kaplan-Meier timeto-event analysis.

Cox proportional hazards regression yielded an unadjusted hazard ratio of 0.96 (95\% CI: 0.84-1.11) when comparing time to first rheumatology visit among patients with $\geq 20 \%$ community poverty level to patients with $<20 \%$ community poverty level. Adjusting for sex, race/ethnicity, insurance, reported family education level, patient reported morning stiffness, RF status, and baseline CHAQ score, yielded a hazard ratio of 0.81 (95\% CI: $0.67-0.99, p=0.038$ ) when comparing time to first rheumatology visit among patients with $\geq 20 \%$ community poverty level to patients with $<20 \%$ community poverty level. This suggests that patients living in areas with $\mathrm{a} \geq 20 \%$ community poverty level were $19 \%$ less likely to be seen by a rheumatologist compared to those living in $<20 \%$ community poverty level at the same time point. Therefore, those individuals living in higher poverty areas experienced delays in first presentation to a pediatric rheumatologist.

In the multivariate Cox analysis (Table 2), public insurance was not a significant predictor of delay in seeing a rheumatologist (HR 1.01, 95\% CI 0.84-1.21, p-value > 0.9 ). Additionally, guardian education level was not found to be a significant predictor (high school or less: HR 0.96, 95\% CI 0.75-1.23, $p$-value $=0.7$; college or junior school: HR 0.97, 95\% CI 0.81-1.17, $p$-value =0.8; graduate school as referent).

Unadjusted sensitivity analysis using family reported income level as the primary predictor demonstrated no statistically significant differences between income groups with time to first rheumatology visit $(p=0.13)$ using Kaplan- Meier analysis. Adjusted sensitivity analyses did not demonstrate a statistically significant difference in time from symptom onset to first visit across all family reported income levels ( $\$ 50-99,999$ : aHR 0.97, 0.79-1.18, $p$-value 0.7; \$25-49,999: aHR 0.91, 0.66-1.26, 


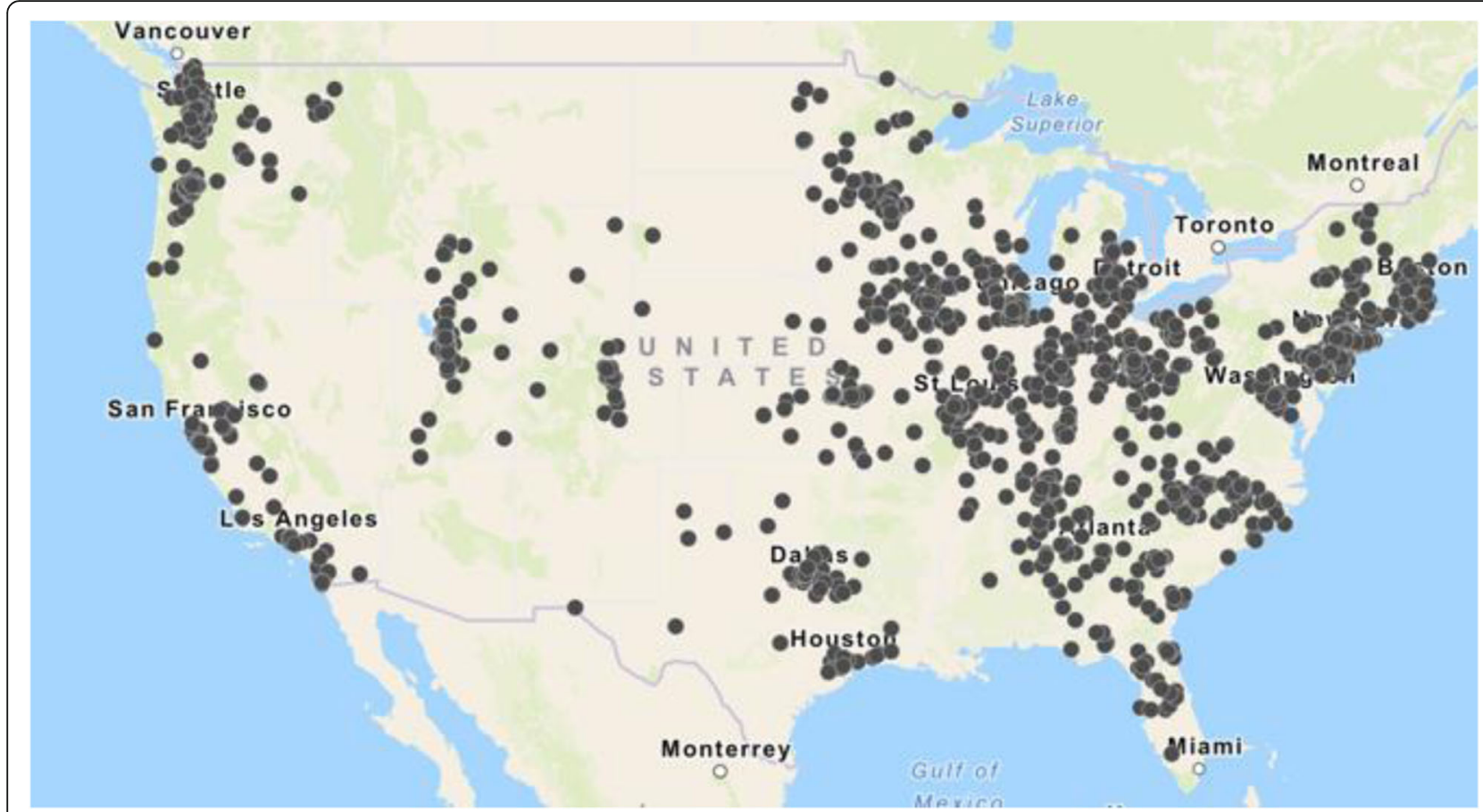

Fig. 1 Geographic distribution of the CARRA pJIA patients included in this study

$p$-value $0.6 ;<\$ 25,000$ : aHR 0.99, 0.69-1.43, $p$-value $>0.9$; reported income of $\geq \$ 100,000$ as referent).

\section{Discussion}

In adjusted analysis for this study, children with newonset polyarticular JIA residing in neighborhoods with $\geq 20 \%$ community poverty experienced delays in presentation to a pediatric rheumatologist as compared to children with pJIA residing in neighborhoods with lower levels of community poverty. Importantly, the impact of

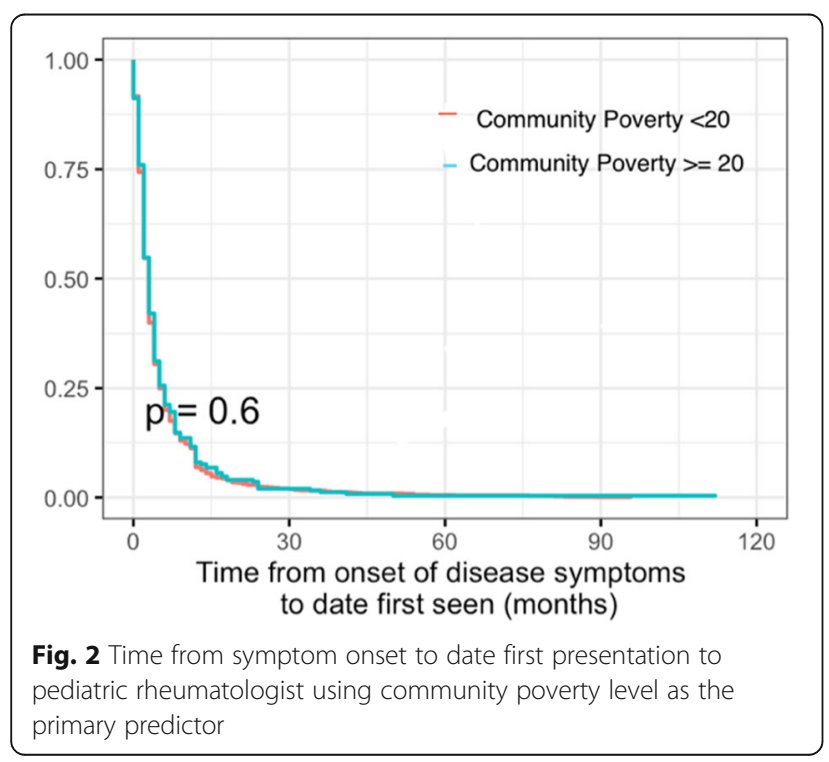

community poverty on delay to rheumatology care was seen even while adjusting for other known social determinants of health, including insurance status and guardian education level (used as a surrogate for health literacy). Such covariates may have acted as negative confounders in the unadjusted model, accounting for the absence of association that was subsequently identified upon adjustment in the multivariate Cox regression analysis. The presence of delays despite adjustment for other social determinants suggests the direct effect of community poverty on delays to care not mediated through other $\mathrm{SDoH}$.

Several intermediate events must occur during the time from symptom onset to diagnosis, and ultimately treatment [14-16]. These events include the recognition of symptoms, visit to a primary care provider, time to referral to a specialist, and time between referral and attending a specialist appointment. While the data used in this study could not truly reflect the steps in this process to help decipher where there was greatest delay, they suggest that community poverty may lead to delays in the overall process of presenting to subspecialty care. Potential factors contributing to delays could include absence of a regular medical home/primary care, lack of transportation, inability to afford costly co-pays associated with subspecialty care, and inability for families to miss work for scheduled appointments. Steps in this process amenable to intervention are critical to identify. 
Table 2 Cox proportional hazard estimate of effect of community poverty level, demographics, and disease characteristics on time to first rheumatologist visit

\begin{tabular}{|c|c|c|c|}
\hline \multirow[b]{2}{*}{ Characteristic } & \multirow[b]{2}{*}{$H R^{2}$} & \multicolumn{2}{|l|}{ Adjusted $^{1}$} \\
\hline & & $95 \% \mathrm{Cl}^{3}$ & $p$-value \\
\hline \multicolumn{4}{|l|}{ Community Poverty Level } \\
\hline$<20 \%$ & - & - & - \\
\hline$\geq 20 \%$ & 0.81 & $0.67-0.99$ & 0.038 \\
\hline \multicolumn{4}{|l|}{ Sex } \\
\hline Male & - & - & - \\
\hline Female & 1.06 & $0.88-1.27$ & 0.600 \\
\hline \multicolumn{4}{|l|}{ Race/Ethnicity } \\
\hline White & - & - & - \\
\hline Asian & 1.14 & $0.73-1.77$ & 0.600 \\
\hline Black, African American, African or Afro-Caribbean & 1.41 & $0.91-2.16$ & 0.120 \\
\hline Hispanic, Latino, or Spanish origin & 1.33 & $1.01-1.76$ & 0.043 \\
\hline Other & 1.21 & $1.21-4.10$ & 0.200 \\
\hline Prefer not to answer & 2.23 & $1.21-4.10$ & 0.010 \\
\hline \multicolumn{4}{|l|}{ Insurance } \\
\hline Private & - & - & - \\
\hline Public & 1.01 & $0.84-1.21$ & $>0.90$ \\
\hline \multicolumn{4}{|l|}{ Reported Family Education Level } \\
\hline Graduate School & - & - & - \\
\hline College, Junior College, or Technical School & 0.97 & $0.81-1.17$ & 0.800 \\
\hline High School or Less & 0.96 & $0.75-1.23$ & 0.700 \\
\hline \multicolumn{4}{|l|}{ Patient Reported Morning Stiffness } \\
\hline$\leq 15 \min$ & - & - & - \\
\hline$>15 \min$ & 1.12 & $0.93-1.36$ & 0.200 \\
\hline \multicolumn{4}{|l|}{ Anti-CCP } \\
\hline Negative & - & - & - \\
\hline Positive & 0.99 & $0.73-1.35$ & $>0.90$ \\
\hline Not Done & 1.04 & $0.88-1.24$ & 0.600 \\
\hline \multicolumn{4}{|l|}{$\lg M \mathrm{RF}$} \\
\hline Negative & - & - & - \\
\hline Positive & 0.94 & $0.70-1.25$ & 0.700 \\
\hline Not Done & 1.14 & $0.79-1.65$ & 0.500 \\
\hline Baseline CHAQ & 0.91 & $0.80-1.03$ & 0.140 \\
\hline
\end{tabular}

1: Cox-proportional hazard model stratified by age at baseline $(>9$ and $<=9)$ adjusting for sex, race/ethnicity, insurance, reported family education level, patient reported morning stiffness, anti-CCP, RF IgM, and baseline CHAQ

2: Hazard ratio

3: Confidence interval

4: Child Health Assessment Questionnaire

It is worth noting that the pJIA CARRA Registry cohort is unlikely to reflect the full diversity of the population of children with pJIA in the US. Our pJIA cohort was comprised of $74 \%$ White children (compared to $81 \%$ in 2017 and $93 \%$ in 2013) [22, 23] with $20 \%$ reporting an income level $<\$ 50,000 /$ year (compared to $8.9 \%$ in 2013 ) [22]. A recent publication from the Children's Hospital of Philadelphia has shown more racial diversity in their
pJIA cohort, including a higher proportion (13\%) [24] of Black patients (compared to $3.7 \%$ in our cohort). Overall, the demographic characteristics of our cohort of the CARRA Registry patients are predominantly White, affluent, educated, and privately insured. Our participants' families were more educated than average $(56.2 \%$ with college degree or higher versus $32 \%$ in the average US population [25]), had higher wealth (53.2\% of the cohort 
reporting at least $\$ 50,000 /$ year income compared to the US median income of $\$ 62,843$ [25]), and had lower rates of public insurance $(25.5 \%$ versus $35 \%$ among all US children [26]). A publication from Cincinnati Children's showed that Medicaid insurance was utilized most often by non-White children with JIA $(p=0.04)$ [27]. The paucity of minority recruits in the CARRA pJIA cohort might explain discrepancies in the percentage of children with public insurance in our study. In the 20152019 ACS 5-year estimates, 21.1\% of the population lived in census tracts with poverty rates of $20 \%$ or higher with a sizable portion of these communities in the Midwest and the South [28]. In our cohort, 19\% of patients lived in communities with $\geq 20 \%$ community poverty and as seen in Fig. 1, most patients resided on the East and West coasts of the US.

The absence of diversity in our cohort highlights the need to prioritize and improve diverse patient enrollment in pediatric registries to improve generalizability of research results and to be able to more accurately understand the relationship between social determinants of health, including socioeconomic status and racial disparities, and disease outcomes. From a public health perspective, it is imperative to ensure early referral and intervention for children across different socioeconomic statuses to promote equal and timely access to quality health care.

\section{Strengths}

The strength of this study is the large sample of patients from the CARRA Registry. An additional advantage was our retrospective cohort study design which allowed for time-to-event analyses and calculation of hazard ratios as many prior studies of socioeconomic status in JIA have been cross-sectional in nature with interpretation limited to association.

\section{Limitations}

While this CARRA cohort may not be demographically representative of the overall pJIA population as described previously, the large sample size has given us the opportunity to study the effect of community poverty as a potentially modifiable key step in the long-term care of these patients. Furthermore, we expect that the lack of diversity would bias our study towards the null, and therefore does not threaten the validity of our findings.

We encountered significant missingness in our dataset for key variables such as household education level (28.4\%) and predictors such as reported income level (26.7\%). Our sensitivity analysis using reported income demonstrated no major differences in time to first pediatric rheumatologist visit on Kaplan-Meier analysis and the Cox model. Importantly, due to the reluctance of lower income earners to report financial details, this was likely a nonrandom nonresponse [29]. Therefore, this may not reflect the true underlying relationship between income level and time to first rheumatology visit. To control for baseline disease activity, morning stiffness of less than or equal to 15 min was used due to inability to calculate the cJADAS for a significant portion of our cohort. Morning stiffness of less than or equal to $15 \mathrm{~min}$ may not reliably discern mild, moderate, or severe disease activity at disease onset; therefore, there is the possibility of residual confounding in our model such that cautious interpretation is suggested.

Finally, this analysis does not address the role that SDoH may play in longitudinal disease activity or disease damage which will be the subject of future work.

\section{Conclusion}

Our study found evidence of community poverty as a predictor of delayed time to rheumatology care in newly diagnosed pJIA patients. Further studies should focus on the intersection of economic deprivation and racial disparities, which have been previously suggested in studies from an earlier iteration of the CARRA Registry [22, 23]. Further identification of specific barriers that delay presentation to a pediatric rheumatologist may inform critical public health policy change to minimize delays to care and thus improve pJIA disease outcomes.

\section{Acknowledgments}

The authors wish to acknowledge CARRA and the ongoing Arthritis Foundation financial support of CARRA.

This work could not have been accomplished without the aid of the following organizations: The NIH's National Institute of Arthritis and Musculoskeletal and Skin Diseases (NIAMS) \& the Arthritis Foundation. We would also like to thank all participants and hospital sites that recruited patients for the CARRA Registry. The authors thank the following CARRA Registry site principal investigators, sub- investigators and research coordinators:

N. Abel, K. Abulaban, A. Adams, M. Adams, R. Agbayani, J. Aiello, S.

Akoghlanian, C. Alejandro, E. Allenspach, R. Alperin, M. Alpizar, G. Amarilyo, W. Ambler, E. Anderson, S. Ardoin, S. Armendariz, E. Baker, I. Balboni, S.

Balevic, L. Ballenger, S. Ballinger, N. Balmuri, F. Barbar-Smiley, L. Barillas-Arias, M. Basiaga, K. Baszis, M. Becker, H. Bell-Brunson, E. Beltz, H. Benham, S. Benseler, W. Bernal, T. Beukelman, T. Bigley, B. Binstadt, C. Black, M. Blakley, J. Bohnsack, J. Boland, A. Boneparth, S. Bowman, C. Bracaglia, E. Brooks, M. Brothers, A. Brown, H. Brunner, M. Buckley, M. Buckley, H. Bukulmez, D. Bullock, B. Cameron, S. Canna, L. Cannon, P. Carper, V. Cartwright, E. Cassidy, L. Cerracchio, E. Chalom, J. Chang, A. Chang-Hoftman, V. Chauhan, P. Chira, T. Chinn, K. Chundru, H. Clairman, D. Co, A. Confair, H. Conlon, R. Connor, A. Cooper, J. Cooper, S. Cooper, C. Correll, R. Corvalan, D. Costanzo, R. Cron, L. Curiel-Duran, T. Curington, M. Curry, A. Dalrymple, A. Davis, C. Davis, C. Davis, T. Davis, F. De Benedetti, D. De Ranieri, J. Dean, F. Dedeoglu, M. DeGuzman, N. Delnay, V.

Dempsey, E. DeSantis, T. Dickson, J. Dingle, B. Donaldson, E. Dorsey, S. Dover, J. Dowling, J. Drew, K. Driest, Q. Du, K. Duarte, D. Durkee, E. Duverger, J.

Dvergsten, A. Eberhard, M. Eckert, K. Ede, B. Edelheit, C. Edens, C. Edens, Y.

Edgerly, M. Elder, B. Ervin, S. Fadrhonc, C. Failing, D. Fair, M. Falcon, L. Favier,

S. Federici, B. Feldman, J. Fennell, I. Ferguson, P. Ferguson, B. Ferreira, R. Ferrucho, K. Fields, T. Finkel, M. Fitzgerald, C. Fleming, O. Flynn, L. Fogel, E. Fox, M. Fox, L. Franco, M. Freeman, K. Fritz, S. Froese, R. Fuhlbrigge, J. Fuller, N.

George, K. Gerhold, D. Gerstbacher, M. Gilbert, M. Gillispie-Taylor, E. Giverc, C. Godiwala, I. Goh, H. Goheer, D. Goldsmith, E. Gotschlich, A. Gotte, B. Gottlieb, C. Gracia, T. Graham, S. Grevich, T. Griffin, J. Griswold, A. Grom, M. Guevara, P. Guittar, M. Guzman, M. Hager, T. Hahn, O. Halyabar, E. Hammelev, M. Hance, A. Hanson, L. Harel, S. Haro, J. Harris, O. Harry, E. Hartigan, J. Hausmann, A. 
Hay, K. Hayward, J. Heiart, K. Hekl, L. Henderson, M. Henrickson, A. Hersh, K. Hickey, P. Hill, S. Hillyer, L. Hiraki, M. Hiskey, P. Hobday, C. Hoffart, M. Holland, M. Hollander, S. Hong, M. Horwitz, J. Hsu, A. Huber, J. Huggins, J. Hui-Yuen, C Hung, J. Huntington, A. Huttenlocher, M. Ibarra, L. Imundo, C. Inman, A. Insalaco, A. Jackson, S. Jackson, K. James, G. Janow, J. Jaquith, S. Jared, N. Johnson, J. Jones, J. Jones, J. Jones, K. Jones, S. Jones, S. Joshi, L. Jung, C. Justice, A. Justiniano, N. Karan, K. Kaufman, A. Kemp, E. Kessler, U. Khalsa, B. Kienzle, S. Kim, Y. Kimura, D. Kingsbury, M. Kitcharoensakkul, T. Klausmeier, K. Klein, M. Klein-Gitelman, B. Kompelien, A. Kosikowski, L. Kovalick, J. Kracker, S. Kramer, C. Kremer, J. Lai, J. Lam, B. Lang, S. Lapidus, B. Lapin, A. Lasky, D. Latham, E. Lawson, R. Laxer, P. Lee, P. Lee, T. Lee, L. Lentini, M. Lerman, D. Levy, S. Li, S. Lieberman, L. Lim, C. Lin, N. Ling, M. Lingis, M. Lo, D. Lovell, D. Lowman, N. Luca, S. Lvovich, C. Madison, J. Madison, S. Magni Manzoni, B. Malla, J. Maller, M. Malloy, M. Mannion, C. Manos, L.. Marques, A. Martyniuk, T. Mason, S. Mathus, L. McAllister, K. McCarthy, K. McConnell, E. McCormick, D. McCurdy, P. McCurdy Stokes, S. McGuire, I. McHale, A. McMonagle, C. McMullen-Jackson, E. Meidan, E. Mellins, E. Mendoza, R. Mercado, A. Merritt, L. Michalowski, P. Miettunen, M. Miller, D. Milojevic, E. Mirizio, E. Misajon, M. Mitchell, R. Modica, S. Mohan, K. Moore, L. Moorthy, S. Morgan, E. Morgan Dewitt, C. Moss, T. Moussa, V. Mruk, A. Murphy, E. Muscal, R. Nadler, B. Nahal, K. Nanda, N. Nasah, L. Nassi, S. Nativ, M. Natter, J. Neely, B. Nelson, L. Newhall, L. Ng, J. Nicholas, R. Nicolai, P. Nigrovic, J. Nocton, B. Nolan, E. Oberle, B. Obispo, B. O'Brien, T. O'Brien, O. Okeke, M. Oliver, J. Olson, K. O'Neil, K. Onel, A. Orandi, M. Orlando, S. Osei-Onomah, R. Oz, E. Pagano, A. Paller, N. Pan, S. Panupattanapong, M. Pardeo, J. Paredes, A. Parsons, J. Patel, K. Pentakota, P. Pepmueller, T. Pfeiffer, K. Phillippi, D. Pires Marafon, K. Phillippi, L. Ponder, R. Pooni, S. Prahalad, S. Pratt, S. Protopapas, B. Puplava, J. Quach, M. QuinlanWaters, C. Rabinovich, S. Radhakrishna, J. Rafko, J. Raisian, A. Rakestraw, C. Ramirez, E. Ramsay, S. Ramsey, R. Randell, A. Reed, A. Reed, A. Reed, H. Reid, K. Remmel, A. Repp, A. Reyes, A. Richmond, M. Riebschleger, S. Ringold, M. Riordan, M. Riskalla, M. Ritter, R. Rivas-Chacon, A. Robinson, E. Rodela, M. Rodriquez, K. Rojas, T. Ronis, M. Rosenkranz, B. Rosolowski, H. Rothermel, D. Rothman, E. Roth-Wojcicki, K. Rouster - Stevens, T. Rubinstein, N. Ruth, N. Saad, S. Sabbagh, E. Sacco, R. Sadun, C. Sandborg, A. Sanni, L. Santiago, A. Sarkissian, S. Savani, L. Scalzi, L. Schanberg, S. Scharnhorst, K. Schikler, A. Schlefman, H. Schmeling, K. Schmidt, E. Schmitt, R. Schneider, K. SchollaertFitch, G. Schulert, T. Seay, C. Seper, J. Shalen, R. Sheets, A. Shelly, S. Shenoi, K. Shergill, J. Shirley, M. Shishov, C. Shivers, E. Silverman, N. Singer, V. Sivaraman, J. Sletten, A. Smith, C. Smith, J. Smith, J. Smith, E. Smitherman, J. Soep, M. Son, S. Spence, L. Spiegel, J. Spitznagle, R. Sran, H. Srinivasalu, H. Stapp, K. Steigerwald, Y. Sterba Rakovchik, S. Stern, A. Stevens, B. Stevens, R. Stevenson, K. Stewart, C. Stingl, J. Stokes, M. Stoll, E. Stringer, S. Sule, J. Sumner, R. Sundel, M. Sutter, R. Syed, G. Syverson, A. Szymanski, S. Taber, R. Tal, A. Tambralli, A. Taneja, T. Tanner, S. Tapani, G. Tarshish, S. Tarvin, L. Tate, A. Taxter, J. Taylor, M. Terry, M. Tesher, A. Thatayatikom, B. Thomas, K. Tiffany, T. Ting, A. Tipp, D. Toib, K. Torok, C. Toruner, H. Tory, M. Toth, S. Tse, V. Tubwell, M. Twilt, S. Uriguen, T. Valcarcel, H. Van Mater, L. Vannoy, C. Varghese, N. Vasquez, K. Vazzana, R. Vehe, K. Veiga, J. Velez, J. Verbsky, G. Vilar, N. Volpe, E. von Scheven, S. Vora, J. Wagner, L. Wagner-Weiner, D. Wahezi, H. Waite, J. Walker, H. Walters, T. Wampler Muskardin, L. Waqar, M. Waterfield, M. Watson, A. Watts, P. Weiser, J. Weiss, P. Weiss, E. Wershba, A. White, C. Williams, A. Wise, J. Woo, L. Woolnough, T. Wright, E. Wu, A. Yalcindag, M. Yee, E. Yen, R. Yeung, K. Yomogida, Q. Yu, R. Zapata, A. Zartoshti, A. Zeft, R. Zeft, Y. Zhang, Y. Zhao, A. Zhu, C. Zic.

\section{Authors' contributions}

NB, WDS designed, interpreted, drafted and edited this study and manuscript. VC and LG analysed the data set and edited the final draft of the manuscript. EL, KO, SG, BG edited the final draft of the manuscript and provided mentorship along the design of this study. The author(s) read and approved the final manuscript.

\section{Funding}

No outside sources of funding were used for this study.

\section{Availability of data and materials}

The data that support the findings of this study are available from the CARRA Registry but restrictions apply to the availability of these data, which were used under license for the current study, and so are not publicly available. Data are however available from the authors upon reasonable request and with permission of the CARRA Registry.

\section{Declarations}

\section{Ethics approval}

Approval for exemption was obtained from the Hospital for Special Surgery and University of California, San Francisco Institutional Review Board.

\section{Consent for publication}

Not Applicable.

\section{Competing interests}

The authors declare that they have no competing interests.

\section{Author details}

${ }^{1}$ Hospital for Special Surgery, New York, NY, USA. ${ }^{2}$ Weill Cornell Medicine, New York, NY, USA. ${ }^{3}$ University of California, San Francisco, San Francisco, CA, USA.

Received: 5 May 2021 Accepted: 6 June 2021

Published online: 14 August 2021

\section{References}

1. Wallace CA, Huang B, Bandeira M, Ravelli A, Giannini EH. Patterns of clinical remission in select categories of juvenile idiopathic arthritis. Arthritis Rheum. 2005:52(11):3554-62. https://doi.org/10.1002/art.21389.

2. Magni-Manzoni S, Rossi F, Pistorio A, Temporini F, Viola S, Beluffi G, et al. Prognostic factors for radiographic progression, radiographic damage, and disability in juvenile idiopathic arthritis. Arthritis Rheum. 2003;48(12):350917. https://doi.org/10.1002/art.11337.

3. Bowyer SL, Roettcher PA, Higgins GC, Adams B, Myers LK, Wallace C, et al. Health status of patients with juvenile rheumatoid arthritis at 1 and 5 years after diagnosis. J Rheumatol. 2003;30(2):394-400.

4. Mason T, Reed AM, Nelson AM, Thomas KB. Radiographic progression in children with polyarticular juvenile rheumatoid arthritis: a pilot study. Ann Rheum Dis. 2005;64(3):491-3. https://doi.org/10.1136/ard.2003.017053.

5. Wallace CA, Giannini EH, Spalding SJ, Hashkes PJ, O'Neil KM, Zeft AS, et al. Trial of early aggressive therapy in polyarticular juvenile idiopathic arthritis. Arthritis Rheum. 2012:64(6):2012-21. https://doi.org/10.1002/art.34343.

6. Newacheck PW, McManus M, Fox HB, Hung YY, Halfon N. Access to health care for children with special health care needs. Pediatrics. 2000;105(4):7606. https://doi.org/10.1542/peds.105.4.760.

7. Kuhlthau K, Nyman RM, Ferris TG, Beal AC, Perrin JM. Correlates of use of specialty care. Pediatrics. 2004;113(3):e249-55. https://doi.org/10.1542/ peds.113.3.e249.

8. Goodman SM, Mandl LA, Mehta B, Navarro-Millan I, Russell LA, Parks ML, et al. Does education level mitigate the effect of poverty on Total knee arthroplasty outcomes? Arthritis Care Res (Hoboken). 2018;70(6):884-91. https://doi.org/10.1002/acr.23442.

9. Diez Roux AV. Investigating neighborhood and area effects on health. Am J Public Health. 2001;91(11):1783-9. https://doi.org/10.2105/AJPH.91.11.1783.

10. Krieger N, Chen JT, Waterman PD, Rehkopf DH, Subramanian SV. Painting a truer picture of US socioeconomic and racial/ethnic health inequalities: the public health disparities geocoding project. Am J Public Health. 2005;95(2): 312-23. https://doi.org/10.2105/AJPH.2003.032482.

11. Chen JT, Rehkopf DH, Waterman PD, Subramanian SV, Coull BA, Cohen B, et al. Mapping and measuring social disparities in premature mortality: the impact of census tract poverty within and across Boston neighborhoods, 1999-2001. J Urban Health. 2006;83(6):1063-84. https://doi.org/10.1007/s11 524-006-9089-7.

12. Yang G, Bykerk VP, Boire G, Hitchon CA, Thorne JC, Tin D, et al. Pope JE: $\mathrm{CATCH}$ investigators. Does socioeconomic status affect outcomes in early inflammatory arthritis? Data from a Canadian multisite suspected rheumatoid arthritis inception cohort. J Rheumatol. 2015;42(1):46-54. https://doi.org/10.3899/jrheum.131382 Epub 2014 Nov 15. PMID: 25399388.

13. Baldassari AR, Cleveland RJ, Luong MN, et al. Socioeconomic factors and self-reported health outcomes in African Americans with rheumatoid arthritis from the Southeastern United States: the contribution of childhood socioeconomic status. BMC Musculoskelet Disord. 2016;17:10. Published 2016 Jan 12. https://doi.org/10.1186/s12891-016-0882-5.

14. Kumar K, Daley E, Carruthers DM, Situnayake D, Gordon C, Grindulis K, et al. Delay in presentation to primary care physicians is the main reason why patients with rheumatoid arthritis are seen late by rheumatologists. 
Rheumatology (Oxford). 2007;46(9):1438-40. https://doi.org/10.1093/rheuma tology/kem130.

15. Foster HE, Eltringham MS, Kay LJ, Friswell M, Abinun M, Myers A. Delay in access to appropriate care for children presenting with musculoskeletal symptoms and ultimately diagnosed with juvenile idiopathic arthritis. Arthritis Rheum. 2007;57(6):921-7. https://doi.org/10.1002/art.22882.

16. Oen K, Tucker L, Huber AM, Miettunen P, Scuccimarri R, Campillo S, et al. Predictors of early inactive disease in a juvenile idiopathic arthritis cohort: results of a Canadian multicenter, prospective inception cohort study. Arthritis Rheum. 2009;61 (8):1077-86. https://doi.org/10.1002/art.24539.

17. Pruunsild C, Uibo K, Liivamagi H, Tarraste S, Talvik T, Pelkonen P. Prevalence and short-term outcome of juvenile idiopathic arthritis: a population-based study in Estonia. Clin Exp Rheumatol. 2007;25(4):649-53.

18. Subramanian SV, Chen JT, Rehkopf DH, Waterman PD, Krieg-er N. Comparing individual- and area-based socioeconomic measures for the surveillance of health disparities: a multilevel analysis of Massachusetts births, 1989-1991. Am J Epidemiol. 2006;164(9):823-34. https://doi.org/10.1 093/aje/kwj313.

19. Krieger N, Chen JT, Waterman PD, Rehkopf DH, Subramanian SV. Race/ ethnicity, gender, and monitoring socioeconomic gradients in health: a comparison of area-based socioeconomic measures: the public health disparities geocoding project. Am J Public Health. 2003;93(10):1655-71. https://doi.org/10.2105/A.JPH.93.10.1655.

20. Singh G, Athreya BH, Fries JF, Goldsmith DP. Measurement of health status in children with juvenile rheumatoid arthritis. Arthritis Rheum. 1994;37(12): 1761-9. https://doi.org/10.1002/art.1780371209.

21. Consolaro A, Negro G, Chiara Gallo M, Bracciolini G, Ferrari C, Schiappapietra $B$, et al. Defining criteria for disease activity states in nonsystemic juvenile idiopathic arthritis based on a three-variable juvenile arthritis disease activity score. Arthritis Care Res (Hoboken). 2014;66(11):1703-9. https://doi.org/10.1 002/acr.22393 PMID: 24980508

22. Ringold S, Beukelman T, Nigrovic PA, Kimura Y. CARRA registry site principal investigators. Race, ethnicity, and disease outcomes in juvenile idiopathic arthritis: a cross-sectional analysis of the childhood arthritis and rheumatology research Alliance (CARRA) registry. J Rheumatol. 2013;40(6): 936-42. https://doi.org/10.3899/jrheum.121147.

23. Beukelman T, Kimura Y, llowite NT, Mieszkalski K, Natter MD, Burrell G, et al. The new Childhood Arthritis and Rheumatology Research Alliance (CARRA) registry: design, rationale, and characteristics of patients enrolled in the first 12 months. Pediatr Rheumatol Online J. 2017;15(1):30. https://doi.org/10.11 86/s12969-017-0160-6.

24. Chang JC, Xiao R, Burnham JM, Weiss PF. Longitudinal assessment of racial disparities in juvenile idiopathic arthritis disease activity in a treat-to-target intervention. Pediatr Rheumatol Online J. 2020;18(1):88. https://doi.org/10.11 86/s1 2969-020-00485-y PMID: 33187519; PMCID: PMC7666526.

25. U.S. Census Bureau QuickFacts: United States. Census Bureau QuickFacts, 2019. https://www.census.gov/quickfacts/fact/table/US/SBO030212 Accessed 24 Mar 2021.

26. Uninsured Rate for Children Up to 5.5 Percent in 2018. 2018. https://www. census.gov/library/stories/2019/09/uninsured-rate-for-children-in-2018.html Accessed 24 Mar 2021

27. Brunner HI, Taylor J, Britto MT, Corcoran MS, Kramer SL, Melson PG, et al. Differences in disease outcomes between medicaid and privately insured children: possible health disparities in juvenile rheumatoid arthritis. Arthritis Rheum. 2006;55(3):378-84. https://doi.org/10.1002/art.21991.

28. Bishaw A, Benson C, Shrider E, Glassman B. Changes in Poverty Rates and Poverty Areas Over Time: 2005 to 2019. 2021. Census.gov . https://www. census.gov/content/dam/Census/library/publications/2020/acs/acsbr20-008. pdf. Accessed 9 Apr 2021.

29. Moore J, Stinson LL, Welniak EJ Jr. Income measurement error in surveys. J Off Stat. 2000;16(4):331-61.

\section{Publisher's Note}

Springer Nature remains neutral with regard to jurisdictional claims in published maps and institutional affiliations.

\section{Ready to submit your research? Choose BMC and benefit from:}

- fast, convenient online submission

- thorough peer review by experienced researchers in your field

- rapid publication on acceptance

- support for research data, including large and complex data types

- gold Open Access which fosters wider collaboration and increased citations

- maximum visibility for your research: over $100 \mathrm{M}$ website views per year

At BMC, research is always in progress.

Learn more biomedcentral.com/submissions 